\title{
DEZ ANOS DE ANTAGONISMO NAS POLÍTICAS SOBRE ENSINO SUPERIOR EM NÍVEL INTERNACIONAL
}

\author{
Marco Antonio Rodrigues Dias ${ }^{*}$
}

\begin{abstract}
RESUMO: O autor, ex-vice-reitor e professor aposentado da UNB, foi, durante mais de 17 anos, diretor da Divisão de Ensino Superior da UNESCO (1981-1999), supervisionou a elaboração dos documentos de política do ensino superior da UNESCO e coordenou a organização da Conferência Mundial sobre Ensino Superior (CMES) desta organização, em 1998. Considera que sobre este tema não há neutralidade, em particular no seu caso, em função das responsabilidades que exerceu durante quase duas décadas na UNESCO. Recorda que, há dez anos, dois documentos sobre políticas do ensino superior foram publicados em nível internacional, pelo Banco Mundial e pela UNESCO, ambos partindo de diagnósticos semelhantes, mas chegando a conclusóes e elaborando propostas totalmente divergentes, fruto de uma visão radicalmente diversa da sociedade, uns vendo-a como instrumento para reforçar o mercado, outros como uma entidade coletiva que deve ser considerada segundo suas especificidades sociais e culturais. Hoje, com a intervenção de novos atores, a Organização Mundial do Comércio, por exemplo, a posição de funcionários dessas duas organizações torna-se mais próxima, sendo impossível prever que orientação adotarão, no futuro, a comunidade acadêmica internacional e os Estados-membros dessas organizações.
\end{abstract}

Palavras-chave: Documentos de política sobre ensino superior. Comercialização da educação. Bem público. Serviço público.

Conselheiro especial da Universidade das Naçôes Unidas, professor aposentado da Universidade de Brasília (UNB) e ex-diretor da Divisão de Ensino Superior da UNESCO (1981-1999). E-mail:mardias@wanadoo.fr/marcoantoniodias@yahoo.com 
Dez anos de antagonismo nas políticas sobre ensino superior...

Ten YeARS OF ANTAgONISM AROUND HIGHER EDUCATION POLICIES AT THE INTERNATIONAL LEVEL

ABSTRACT: Ex-vice-director of and retired professor from the UNB, the author was, for over 17 years (1981-1999), the director of the UNESCO Higher Education Division. He thus supervised the elaboration of the UNESCO higher education policy documents and coordinated the organization of this organization's World Conference on Higher Education, in 1998. He considers that there is no neutrality in that matter, most particularly in his case, because of the responsibilities he assumed during almost two decades at UNESCO. He remembers that, ten years ago, two documents concerning higher education policies were issued at the international level by the World Bank and by the UNESCO. Both were based on similar diagnoses, but came to totally diverse conclusions, since they were the produce of radically different visions of society. One side considered higher education as a tool to consolidate the market, while the other saw it as a collective entity that should be taken into account according to its cultural and social specificities. Nowadays, with the interference of new actors, such as the WTO for example, the officials from these two organizations are getting closer in their positions, and one cannot predict which thrust the academic community and the States members of these organizations will adopt in the future.

Key words: Higher education policy document. Commoditization of education. Public good. Public service.

\section{Introdução}

$P$

ouca gente recordou, mas, dez anos atrás, dois documentos importantes sobre o ensino superior eram lançados em nível internacional. O primeiro deles do Banco Mundial, publicado em 1994, teve como título "Educação superior: aprender com a experiência" ("Higher education - The lessons of experience"). O segundo, lançado pela UNESCO, com uma versão provisória publicada em 1993 e a versão final lançada em Paris em fevereiro de 1995, teve como título "Documento de política para a mudança e o desenvolvimento na educação superior ("Policy paper for change and development in higher education").

Partindo de diagnósticos semelhantes: constatação do incremento dos efetivos na educação superior, problemas de financiamento generalizados, diversificação das instituições, para citar apenas algumas 
das questões mais visíveis ali tratadas, esses documentos representavam, em realidade, duas visões absolutamente opostas sobre a função da educação superior com relação à sociedade e sobre a própria sociedade.

Ambos os documentos tiveram grande influência no desenvolvimento de políticas educacionais no mundo inteiro e as questôes neles colocadas continuam, hoje, passados dez anos, a ser objeto de discussões em todos os fóruns internacionais consagrados a este nível da educação.

De 1994 para cá, o Banco Mundial deu seguimento às reflexões sobre a problemática do ensino superior, publicando no ano 2000 o informe de um grupo de trabalho intitulado "Higher education in developing countries - peril and promises" e, mais recentemente, em 2002, um livro: Constructing knowledge societies: new challenges for tertiary education.

Parece evidente que, neste volume, os responsáveis pelo setor de educação do Banco tentam apresentar uma visão mais coerente dos problemas vinculados à relação entre educação superior e sociedade e, ao mesmo tempo, num reconhecimento implícito de erros anteriores de apreciação, procuram mostrar que educação superior não pode ser vista apenas como um subsetor discreto dentro do setor educacional e que, ao contrário, é peça fundamental de um sistema holístico que deve se tornar mais flexível, diversificado, eficiente e responsável diante da economia do conhecimento.

A UNESCO, por sua vez, depois de lançar seu documento de políticas para o ensino superior, buscou, de seu lado, estimular, no mundo inteiro, reflexóes sobre o tema. Do ponto de vista concreto, mostrando idéias de que educação superior é um bem público e de que a cooperação solidária não é uma utopia irrealista, lançou um programa de cooperação - UNITWIN - Cátedras UNESCO - que, segundo opinião geral, apesar de não ser perfeito (a própria UNESCO jamais lhe concedeu nem a prioridade nem os fundos solicitados pelos próprios Estados-membros), é considerado um sucesso. Esse programa atinge, hoje, mais de 500 projetos espalhados pelo mundo inteiro com financiamento de fontes as mais diversas, nacionais e internacionais.

Por sua vez, no período de 1995 a 1998, por intermédio de seus escritórios regionais ou em cooperação com organizações não-governamentais e governamentais, promoveu uma série de encontros e lançou 
Dez anos de antagonismo nas políticas sobre ensino superior...

uma série de publicações que tiveram grande impacto no mundo inteiro e que culminaram com a realização da Conferência Mundial sobre o Ensino Superior (CMES) que reuniu em Paris, em outubro de 1998, quase 5 mil participantes, mais de 180 países. Destaque-se que pelo menos 125 delegaçóes oficiais eram presididas por ministros de Estado, número superior ao de ministros que costumam participar nas conferências gerais dessa organização.

Hoje, o documento que reflete a posição oficial da UNESCO avaliada pelos Estados-membros é a "Declaração mundial sobre educação superior no século XXI: visão e ação", adotada pelos participantes da CMES (representantes oficiais de governos, organizaçôes governamentais e não-governamentais, comunidade acadêmica etc.) no dia 9 de outubro de 1998.

O documento de referência do Banco Mundial passou a ser o livro Constructing knowledge societies: new challenges for tertiary education.

$\mathrm{Na}$ prática, hoje, funcionários das duas organizações, às quais se associa a Organização para Cooperação e Desenvolvimento Econômico (OCDE), aproximam suas posiçôes teóricas e práticas, não estando ainda claro como tratarão estes temas os Estados-membros da UNESCO.

Além disso, dois fatores novos sobrepõem-se aos debates. Em primeiro lugar o aparecimento em cena, desde 1995, da Organização Mundial do Comércio, na qual, de maneira clara, representantes de um grupo de países e funcionários dessa organização buscam consolidar a posição de se considerar o ensino superior mais como mercadoria que como bem público. Ao se tentar lançar perspectivas sobre o debate, não se pode deixar de levar em consideração o fato de que, em 1993, os Estados-membros da UNESCO aprovaram uma declaração sobre a diversidade cultural e, agora, empenham-se em grandes discussões, para se chegar a um consenso sobre um texto de convenção sobre o mesmo tema. É evidente que não se pode, ao discutir diversidade cultural, deixar de lado as implicações que definições neste campo terão para o ensino superior.

\section{Visões opostas}

Durante todo o período que antecedeu à elaboração destes dois documentos-base, dez anos atrás, era claro que as duas organizações ti- 
nham visões absolutamente opostas não só sobre o ensino superior, mas em geral sobre educação. O Banco, dada a sua natureza comercial, partia de uma visão economicista da sociedade, ao passo que a UNESCO, com base em sua Carta Constitutiva, seja sob a direção do senegalês Amadou Mahtar M'Bow, seja sobre o comando do catalão-espanhol Federico Mayor, considerava a educação, em seu conjunto, um bem público. Segundo a especialista sueca Berit Olsson, "a UNESCO discute a sociedade como uma entidade coletiva, ao passo que o Banco Mundial dá a impressão de ver a sociedade apenas como um mecanismo para regular o sistema de mercado".

Uma síntese das posições do Banco relativas à educação em geral é encontrada, segundo o educador uruguaio-catalão Miguel Soler Roca, no documento "Prioridades e estratégias da educação - Exame do Banco Mundial" (1996) e, no que diz respeito à UNESCO, no informe da Comissão Internacional sobre a Educação para o Século XXI, "Educação: um tesouro a descobrir" ("Learning: the treasure within"), presidida por Jacques Delors, que atualizou os temas do famoso e excelente informe "Aprender a ser" ("Apprendre à être"), da comissão internacional presidida por Edgar Faure em 1972. O documento da Comissão Delors, embora elaborado por um grupo independente, foi assumido pela UNESCO, podendo-se pois dizer que representa a posição oficial da organização.

Segundo análise de Miguel Soler Roca, "o informe da comissão é um livro aberto no qual educação e outros temas são apresentados com uma definição de causas, efeitos, vínculos, tensões, dúvidas, contradições, alternativas". Já o trabalho do Banco Mundial se refere ao exame de problemas pontuais, sempre sob o ângulo economicista do Banco, sem lugar para controvérsias, dúvidas ou debates. É uma "exposição de um pensamento elaborado previamente, dogmático", como assinala ainda Miguel Soler Roca.

\section{Consideração do contexto}

Aí se identifica um ponto que é comum a todas as análises sobre educação e, em particular, sobre o ensino superior. Em sã consciência, pode-se crer que seja possível examinar o problema da educação fora de seu contexto real? Pode-se imaginar ser possível estabelecer critérios para ações concretas que sejam válidos para o mundo inteiro, para to- 
Dez anos de antagonismo nas políticas sobre ensino superior...

dos os povos, para todas as culturas? Façamos um parêntesis e avancemos um pouco no tempo: podem-se aceitar as análises que certos especialistas, anglo-saxões em particular, andam fazendo nos dias de hoje sobre a cooperação interuniversitária na América Latina, desligada da análise da realidade do continente? Pode a comunidade acadêmica internacional aceitar o que pretende um grupo com representantes de uma dúzia de países que busca desenvolver métodos globais de acreditação, dizendo o que é qualidade aplicada ao mundo inteiro?

O Informe Delors, embora, em matéria de educação superior, não tenha ido aos detalhes do documento de políticas da UNESCO de 1995, tem como um de seus aspectos positivos o de iniciar suas análises com um capítulo denominado "Horizontes" dedicado ao estudo do contexto mundial, analisando a questão demográfica, a globalização, o impacto das novas tecnologias de comunicação, os problemas sociais advindos da exclusão crescente no mundo inteiro, a questão da democracia, a situação da mulher, a interdependência planetária, as diferenças entre crescimento econômico e desenvolvimento humano.

O documento do Banco Mundial, cujos autores indicaram ter consultado a comissão internacional, vai direto a situações concretas assinalando que "a educação é crucial para o crescimento econômico e a redução da pobreza”. Numa postura que é comum em todos os documentos do Banco, em particular sobre educação superior, passa-se a fazer análises e elaborar propostas, sem fazer menção à situação das sociedades que menciona ou às quais se dirige. A situação real, a exclusão, não interessa aos analistas. Fala-se da pobreza, mas jamais de suas causas. E, quando se apresentam soluções, sobretudo na área financeira, não se busca saber se os remédios propostos, em lugar de curar o doente, não vão agravar a sua situação, aumentando as injustiças, o elitismo, a exclusão. E necessário destacar esta postura, recordando a conclusão à qual chegaram os que participaram da preparação da CMEs: antes de se decidir que tipo de universidade se pretende construir, é fundamental saber que tipo de sociedade se busca criar ou consolidar.

Em outras palavras e indo mais fundo na questão, é fundamental discutir se se quer construir uma sociedade mais justa ou consolidar as ineqüidades atuais. Uma posição de neutralidade com relação às causas do subdesenvolvimento, da exploração, da miséria é, sem dúvida, a melhor maneira de se garantir a perpetuidade da ineqüidade. 


\section{Repercussões sobre as propostas}

Quando se chega à parte de propostas concretas de ação, o que se vê? São em realidade quatro as medidas propostas pelo Banco:

1. Privatizar a educação superior, com a segurança de que "continuarão recebendo prioridade aqueles países nos quais se atribua mais importância aos provedores e ao financiamento privados".

2. Anular a gratuidade do ensino superior, por meio da cobrança de matrículas.

3. Estimular a criação, no nível pós-secundário mas não universitário, de instituições terciárias mas não universitárias, capazes de organizar cursos mais breves que respondam mais flexivelmente às demandas do mercado de trabalho.

4. Renunciar a transformar o conjunto das universidades públicas em centros de pesquisa.

Já a Comissão Delors, neste ponto retomando documentos anteriores da UNESCO produzidos por seus setores de Educação (Divisão de Ensino Superior) e de Ciência, afirma peremptoriamente que "os países mais pobres devem se dotar de uma capacidade própria de pesquisa e especialização, constituindo, em particular, pólos regionais de excelência".

Esta postura, por certo, repercute sobre as medidas concretas que propõem seja o Banco seja a comissão internacional. Para o Banco Mundial, já que a educação é vista como investimento mais que como direito, é necessário, em primeiro lugar, reduzir seus custos. Para isso, será útil aumentar o coeficente professor-alunos, o que, se levado às últimas conseqüências, significará mais alunos e menos professores. Daí a indicar que será útil a redução do número de laboratórios vai um passo facilmente alcançável. A redução dos salários dos professores também é recomendada. Ninguém estranhará, pois, que se proponha ainda apoio ao ensino privado e ao financiamento privado e, também, que se confie a grupos particulares a gestão da produção e a distribuição dos textos escolares.

Já a comissão claramente solicita que a educação não seja dominada pelo mercado e sugere que a parte do PNB dedicada à educação não seja nunca inferior a $6 \%$. E ainda propõe que se reduza a dívida externa para poder aumentar os gastos com educação. Propõe também que se melhorem as condiçôes do pessoal docente, relembrando que 
Dez anos de antagonismo nas políticas sobre ensino superior...

nenhuma reforma da educação jamais teve êxito atuando sem o apoio do professorado. A comissão poderia ter ido mais adiante fazendo o que fez a Conferência Mundial sobre o Ensino Superior que considerou, no artigo $10 \mathrm{da}$ "Declaração mundial sobre educação superior no século XXI: visão e ação":

uma política vigorosa de desenvolvimento de pessoal é elemento essencial para instituições de educação superior. Devem ser estabelecidas políticas claras relativas a docentes de educação superior que atualmente devem estar ocupados sobretudo em ensinar seus estudantes a aprender a tomar iniciativas, ao invés de serem unicamente fontes de conhecimento. Devem ser tomadas providências adequadas para pesquisar, atualizar e melhorar as habilidades pedagógicas, por meio de programas apropriados de desenvolvimenbto de pessoal, estimulando a inovação constante dos currículos e dos métodos de ensino e de aprendizagem, que assegurem as condições profissionais e financeiras apropriadas ao profissional, garantindo assim a excelência em pesquisa e ensino, de acordo com as provisões da Recomendação referente ao Estado do Pessoal Docente da Educação Superior aprovada pela Conferência Geral da UNESCO em novembro de 1997.

\section{Implicações para o ensino superior}

Os elementos acima mencionados revelam, por si, que é natural que divergências aparecessem também em documentos elaborados uma década atrás e que se referiam especificamente ao ensino superior.

Vamos por partes. O documento do Banco Mundial, de 1994, mantém a perspectiva de um economista, cuja principal preocupação seja a do uso eficiente dos recursos públicos e é a esse objetivo que os formuladores de políticas devem dar prioridade. As posições do Banco tendem sempre a ser dogmáticas, ao contrário daquelas apresentadas no documento de políticas da UNESCO que, resultado de um amplo processo de consulta, visam mais à criação de um quadro conceitual amplo que permita a tomada de decisóes segundo cada quadro cultural específico.

Um ponto fundamental nesta altura dos debates era, como é agora, o do financiamento da educação em geral, do ensino superior em particular. Para a UNESCO, a responsabilidade do poder público neste caso é clara. O Banco desenvolve, desde então, opinióes e atitudes visivelmente contraditórias. Reconhece a importância dos investimentos 
em educação superior, importantes para o crescimento econômico porque melhoram a produtividade individual e, em largo prazo, os rendimentos econômicos da pesquisa e do desenvolvimento tecnológico, o que colabora com a redução da pobreza.

Mas considera que as taxas de rendimento social no ensino superior são inferiores às dos níveis primário e secundário, cujo impacto é maior na redução da pobreza. Por isso, o Banco solicita que o ensino primário e o secundário recebam uma atenção diferenciada e, no caso do ensino superior, o compartir custos (leia-se estimular o ensino pago) e fomentar a educação superior privada colaborariam com a necessidade de investir mais na educação básica e ainda por cima reduziriam os custos públicos da educação superior.

\section{Financiamento e retorno social}

Não se fala, evidentemente no Consenso de Washington, mas estas medidas se encaixam nas propostas do Consenso visando a reduzir a presença do Estado nos gastos sociais.

Vale a pena deter-se um pouco neste tema, difícil para leigos em matéria de economia. Quando se discute a questão, as posições são dogmáticas, os termos utilizados não são os de conhecimento e utilização geral, quem é leigo acaba ficando atemorizado, sente que está sendo manipulado, mas tem dificuldades de reagir ou mesmo de levar adiante um debate. Fica naquela posição de enfrentar um interlocutor que, claramente, o faz sentir-se um ignorante.

A verdade é que, até hoje, muitos economistas e analistas centram o debate nas diferenças entre os retornos sociais e privados ou individuais, comparando o que ganham os indivíduos com os benefícios que recebe a sociedade pelas inversões feitas em educação, em particular na educação superior. Por meio de análises em que os sofismas se multiplicam, defendem que os rendimentos para a sociedade são mais importantes na educação primária e, utilizando um atalho muito ligeiro, concluem que os países em desenvolvimento não devem considerar prioritária a educação superior. Ao contrário, assinalam, devem reduzir ou eliminar os gastos neste setor da educação.

Peter Atherson, um professor infelizmente já falecido, da Brock University no Canadá, recordava, no final dos anos de 1980, que este 
Dez anos de antagonismo nas políticas sobre ensino superior...

método de análise trata do custo econômico da aquisição como uma inversão (financeira) e o compara com as vantagens econômicas. Uma taxa de rentabilidade pessoal (vantagens mais elevadas para a vida individual) expressa o rendimento da inversão do indivíduo em sua própria instrução (direitos, materiais e anos sacrificados etc.). Uma taxa de rentabilidade social significa o rendimento da inversão total em educação (gastos públicos para programas de formação sob a forma de subvenções diversificadas). A metodologia é semelhante à que se utiliza para calcular o valor atual de uma quantidade que alguém receberá mais tarde.

Recordemos que o economista que mais se destacou defendendo esta idéia foi o Sr. Psacharopoulos, alto funcionário do Banco Mundial no final dos anos de 1980 e início dos anos de 1990. No entanto, este mesmo autor, em publicaçôes mais antigas, afirmava, com muito mais clareza, correção e exatidão, que este método não reflete necessariamente a experiência futura dos jovens diplomados de hoje e é ainda mais improvável que consiga traduzir com exatidão a experiência dos diplomados que abordarão o mercado de trabalho dentro de vários anos, porque se terá tomado hoje tal ou qual decisão com respeito ao investimento.

Notemos que, nos documentos de 2000 e de 2002, os especialistas do Banco Mundial reconhecem que estas análises constituíram um equívoco, mas, de fato, quando se vêm as propostas feitas já no início do século XXI, em realidade, elas estão subjacentes, estão implícitas e as medidas sugeridas, ou seja, por exemplo, a de estimular a privatização e eliminar totalmente a gratuidade, são as mesmas que se baseavam nas considerações sobre retorno social do Sr. Psacharopoulos.

O certo é que, baseando-se em métodos que são incapazes de dizer, por exemplo, o que representará para a sociedade o trabalho de uma nutricionista, às vezes até de um economista..., o que se busca com este tipo de raciocínio - ainda presente nas discussóes atuais - é eliminar ou reduzir os investimentos em educação superior.

Para o documento de políticas da UNESCO, por seu lado, a educação, o ensino superior em particular, não é um investimento financeiro, mas um investimento social que terá um impacto sobre a vida do indivíduo é certo, porém, o que é mais importante, implicará um impacto social em largo prazo no que diz respeito à coesão social e ao desenvolvimento cultural. 
Numa afirmação que mais tarde foi retomada pela CMES, o documento de políticas de fevereiro de 1995 afirmava que:

a) o ensino superior é um dos elementos-chave para se colocar em movimento processos mais amplos que são necessários para se lidar com os desafios do mundo moderno;

b) o ensino superior e outras instituições e organizaçōes científicas e profissionais, por meio de suas funçōes em ensino, treinamento, pesquisa e serviços, representam um fator necessário no desenvolvimento e na implementação das estratégias e políticas de desenvolvimento;

c) é necessária uma nova visão do ensino superior que combine a demanda da universalidade do ensino superior com a exigência de maior relevância, para que seja possível dar resposta às expectativas da sociedade na qual exerce suas funçôes. Essa visão dá ênfase aos princípios de liberdade acadêmica e de autonomia institucional, ao mesmo tempo em que enfatiza a necessidade de se prestar contas à sociedade.

\section{Propostas diversificadas}

Como assinalamos no início, os documentos, cujo décimo aniversário se atinge agora, partiram de diagnósticos comuns. Quando se chega às propostas para solucionar os problemas, o Banco Mundial prescreve:

- estimular a diversificação institucional, reforçando o setor privado;

- redefinir o papel do governo com respeito a sua relação com o ensino superior;

- concentrar todos os esforços na questão da qualidade e da eqüidade.

O documento do Banco não chega a propor a extinção das instituiçóes públicas - seria irrealista - mas ataca seus fundamentos por intermédio da questão do financiamento, sugerindo maior investimento privado nessas instituiçôes, concessão de apoio financeiro para estudantes qualificados sem recursos e incentivos para se conseguir mais efici- 
Dez anos de antagonismo nas políticas sobre ensino superior...

ência na definição dos recursos públicos, o que significa, na prática, reduzir os fundos aplicados na educação superior.

Para lograr estes objetivos, o Banco recomendava então uma série de medidas que começaram a ser apresentadas, concretamente, aos governos durante as negociações de empréstimos feitos pelos países. Destaque-se que, muitas vezes, seus representantes, ao negociarem empréstimos que nada tinham a ver com educação superior, passaram a tentar incluir estes itens nas negociaçóes. Foi o que ocorreu, por exemplo, nas discussóes com o ministro da Educação do Brasil, no governo de Itamar Franco, o Sr. Murílio Hingel, que, de pronto, rechaçou essas propostas. $\mathrm{O}$ mesmo, possivelmente, não terá ocorrido em todos os países em desenvolvimento.

Recorde-se que, ao analisar esta questão, a especialista sueca Berit Olsson recordou, com pertinência, que

os dois documentos fornecem conselhos para os que são responsáveis por políticas no nível nacional. Uma diferença primordial consiste no fato de que os conselhos da UNESCO podem ser adotados ou descartados pelos Estados-membros sem nenhuma implicação no que diz respeito a oportunidades de empréstimo, enquanto isto pode não ser o caso com as recomendações do Banco Mundial (...).

Entre as medidas propostas pelo Banco estavam:

a) o estabelecimento de um quadro de políticas coerentes, com o reforço da diversificação;

b) uma orientação de mercado para implementar as políticas, em particular no que se refere à gestão dos estabelecimentos de ensino superior;

c) uma maior autonomia das instituições, autonomia no caso significando não o desenvolvimento da capacidade crítica, mas uma maior descentralização na gestão. Esta autonomia seria acompanhada de medidas visando à prestação de contas das instituições através de critérios precisos de avaliação.

Além disso, mencionava-se a busca de eqüidade e uma melhor resposta às exigências do mercado de trabalho. Não se pensava em vínculos com o mundo do trabalho, mas em maior integração com o setor produtivo, com as empresas, que deveriam estar presentes nos conselhos das universidades. 
Do lado do documento da UNESCO, conforme já foi assinalado, o que se buscou com o documento de políticas não foi o estabelecimento de regras rígidas de caráter universal, mas sim definir um quadro que pudesse ser aplicado nos diversos contextos, segundo as situações sociais e culturais de cada país.

O documento chama a atenção, de partida, ao fato de que, apesar do enorme progresso em muitas áreas do desenvolvimento humano, o mundo de hoje está cercado de tremendos problemas e desafios, dominado pelas mudanças demográficas (em razão do forte aumento populacional em algumas de suas regiōes), por freqüentes conflitos e guerras étnicas, fome, doenças, pobreza persistente, falta de domicílios, desemprego continuado de longo prazo e ignorância, e também por problemas relacionados à proteção do meio ambiente, manutenção da paz, democracia, respeito aos direitos humanos e preservação das diferenças culturais. Para cumprir suas missões, o ensino superior deve enfrentar tendências contraditórias nos campos da democratização, da globalização, da regionalização, da polarização criada por desigualdades, da marginalização de muitos países, da fragmentação que fomenta a discórdia social e cultural.

Uma reforma profunda das estruturas e dos sistemas do ensino superior havia sido previamente identificada como necessária na maioria dos Estados-membros da UNESCO e, para isso, o documento defendeu a necessidade de uma rigorosa auto-análise das instituições sobre seu funcionamento e suas relações com a sociedade em geral, em particular no que diz respeito ao desafio de desenvolver os recursos humanos e reduzir os níveis de pobreza e de marginalização existentes.

Pertinência, qualidade e internacionalização

Para dar base às reformas, o documento de políticas da UNESCO concentra suas análises e propostas dentro de três grandes marcos: pertinência, qualidade e internacionalização.

A pertinência visa a fazer com que as instituições de ensino superior contribuam para o desenvolvimento de uma sociedade mais justa. $\mathrm{O}$ atendimento às necessidades da economia deve ser feito dentro de uma visão em que os valores éticos, a participação e o reforço da democracia estejam presentes. A pertinência implica o uso eficiente de recursos públicos, o que supóe uma prestação de contas à sociedade e 
Dez anos de antagonismo nas políticas sobre ensino superior...

uma gestão eficaz, num marco que preserve a autonomia e as liberdades acadêmicas. A avaliação, no entanto, deve ser vista como instrumento para melhorar a qualidade e a pertinência e não como meio de controle financeiro ou de punição a instituições.

A pertinência implica o desenvolvimento de relações com o mundo do trabalho que não se limitam aos interesses das empresas e uma ação em favor do desenvolvimento do conjunto do sistema educativo, com o qual a educação superior deve interagir ativamente.

A melhoria da qualidade far-se-á por diversos meios, entre os quais a reforma das práticas de ensino e de preparação de programas, com a introdução de estudos multidisciplinares, a utilização de novas tecnologias, desenvolvimento de programas flexíveis e programas de educação permanente. $\mathrm{O}$ desenvolvimento da pesquisa sobre a própria educação superior é considerado indispensável assim como a reforma das políticas relativas ao pessoal das instituições de ensino superior.

A internacionalização, que alguns hoje confundem com comercialização, em nível global, é considerada essencial em primeiro lugar para reduzir os desníveis entre países desenvolvidos e em desenvolvimento, por meio da transferência do conhecimento e da tecnologia, o que implica o desenvolvimento de uma colaboração solidária para ampliar o entendimento intercultural utilizando o intercâmbio de professores, estudantes e pesquisadores. Sabendo-se que nenhuma instituição pode hoje atingir excelência em todos os campos, a cooperação, sobretudo por meio da formação de redes em que os interesses dos participantes sejam comuns, é indispensável.

De uma maneira ultra-sintética, então, pode-se dizer que estes dois documentos os quais, desde então, serviram de base a reflexões mais aprofundadas sobre o ensino superior e que tanta influência exerceram, embora partindo de diagnósticos similares sobre a realidade da educação superior no mundo, caracterizam-se pelos seguintes elementos:

O documento do Banco Mundial "Higher education - The lessons of experience" apresenta uma visão economicista, visando ao uso eficiente de recursos em um quadro de políticas bem definido. Embora mencione a eliminação da pobreza como um objetivo último a alcançar, não se pode dizer que o documento manifeste interesse em que a educação superior enfrente os problemas básicos da sociedade, inclusive as causas da pobreza e da exclusão. 
O documento de políticas da UNESCO, de 1995, apresenta uma visão humanista baseada num contexto de diálogo e de participação. A educação superior é vista como inversão social no longo prazo em busca de uma coesão social.

Para Berit Olsson, "o documento do Banco Mundial apresenta as universidades como problemas para as sociedades. A UNESCO, de sua parte, mantém o foco sobre problemas na sociedade e na necessidade de reforçar as universidades de maneira que elas possam responder melhor a estes desafios e contribuir a uma mudança”.

Quando se analisa a evolução dos estudos sobre ensino superior nos últimos dez anos, assim como os intentos de reforma que se realizaram no mundo durante todo este tempo, não há dúvidas de que o ponto de partida, a explicação de muitas posições, sejam favoráveis a uma integração deste nível de ensino no mercado comercial, sejam os esforços para manter a educação como um direito e como um bem público, encontra a fundamentação dessas posiçôes nestes dois documentos elaborados por volta de 1994.

\section{Evolução dentro do Banco Mundial}

Não é o objetivo deste artigo analisar a evolução ocorrida neste campo, nos últimos dez anos. Em rápidas pinceladas, recordemos o já acima mencionado, que, em 2000, o Banco Mundial publicou o documento "Higher education in developing countries - Peril and promises", resultado de um grupo de trabalho anunciado como de responsabilidade conjunta do Banco e da UNESCO, mas que, em realidade, foi totalmente controlado pelo Banco Mundial (ver p. 41 e 42 de "Perpectivas de la Educación Superior en el Siglo XXI", Fundación Universitaria para la Cooperación Internacional, CRUE, Madrid, 2002).

O documento contou com a colaboração de alguns especialistas competentes, mas a metodologia utilizada era elitista. No momento em que toda a comunidade acadêmica internacional e diversas organizações, inclusive o Banco Mundial, participavam do processo que culminou com a organização da Conferência Mundial de 1998 em Paris, um setor do Banco, que não era o de educação, investia um montante elevado de recursos para confiar a uma universidade norte-americana, que solicitou a colaboração de especialistas de vários países, o direito de fa- 
Dez anos de antagonismo nas políticas sobre ensino superior...

lar em nome do mundo. Por certo, devem-se a esses especialistas - ou pelo menos a alguns deles - progressos na apresentação dos problemas e nas propostas apresentadas. Reconhece-se a importância da educação superior para o desenvolvimento, criticam-se os trabalhos de especialistas do próprio Banco relativos ao retorno social dos diversos níveis de educação, dúvidas são levantadas sobre o fato, antes apresentado como dogma, de que cobrança de matrículas e o ensino pago são fórmulas mágicas para resolver o problema do financiamento da educação superior e, de quebra, colaborar com políticas de eqüidade, enfatiza-se a importância da pesquisa, consideraçóes pertinentes são feitas sobre os sistemas de franquias, vale dizer sobre a comercialização da educação superior.

No entanto, no documento, persiste o receio de se atribuir, como solicitava a CMES, maior responsabilidade aos próprios estudantes no processo educativo. $\mathrm{O}$ medo com relação ao estudante é claro no texto. Com respeito aos efeitos da globalização, a defesa, sem restrição, da privatização é mantida, quando se apresenta a diversificação institucional como sinônimo de qualidade. Há que se recordar que, se há instituições de qualidade organizadas sob o direito privado, como várias universidades católicas ou metodistas na América Latina, tal situação está longe de ser a realidade geral pelo menos neste continente. A relação com o mundo do trabalho continua sendo vista de maneira estreita, destacando-se a defesa dos interesses das empresas e o serviço que as universidades devem prestar às indústrias.

Mais importante, no entanto, é a questão da contextualização. Um dos pontos destacados pelos trabalhos que culminaram com a CMES foi o de que não há qualidade sem pertinência. Não há qualidade se os estabelecimentos de ensino superior não são autônomos, autonomia entendida como vinculada às liberdades acadêmicas e dando condição a professores, pesquisadores e estudantes de exercerem sua capacidade crítica ante os problemas mundiais e nacionais. Não há qualidade se professores e estudantes não são valorizados, se as instituições de ensino superior não estão comprometidas com a busca de solução dos problemas fundamentais da sociedade num momento determinado. A sociedade não se limita às empresas e muito menos às multinacionais. A educação superior não pode viver isolada dos problemas da sociedade, e não pode ignorar, nem deixar de reagir, à redução dos gastos sociais nos países em desenvolvimento por causa da dívida externa, do incre- 
mento da exclusão, da concentração de riquezas. Trata-se, pois, de um documento cuja legitimidade não é clara e que não despertou maior interesse, apesar de conter, como se acentuou acima, elementos que representam uma evolução positiva.

Tal fato explica talvez por que o Banco tenha se apressado em promover imediatamente a elaboração de um outro documento que parece representar, hoje, sua posição oficial: "Constructing knowledge societies: new challenges for tertiary education".

Não se pode dizer que, para a elaboração do documento, consultas não foram feitas. Foram e grandes especialistas foram convidados a exprimir suas opiniōes no mundo inteiro, mas o método ainda não chega a ser legítimo, pois se trata de um processo sempre conduzido por um pequeno grupo. Compreende-se o temor de se proceder a consultas abertas nos meios acadêmicos. Sabe-se onde se começa, mas não se pode prever nunca onde se vai chegar. Mas, apesar das dificuldades, a legitimidade exige um processo amplo de consultas.

É verdade que o grupo de direção é constituído por especialistas e funcionários que, dentro do Banco Mundial, notabilizaram-se por sua capacidade de diálogo e pela tentativa de fundamentar suas posições na realidade, fato que os levou, por exemplo, pelo menos aparentemente, a rechaçar posições políticas e ideológicas radicais como as do Sr. Psacharopoulos, o qual, nos anos de 1980, tanto insistiu em dizer que o retorno social da educação superior não justificava os investimentos que nesse nível faziam países em desenvolvimento, em particular na América Latina.

O documento aponta as vantagens da utilização das novas tecnologias, mas não desconhece os problemas que esta pode criar aumentando a brecha entre países desenvolvidos e subdesenvolvidos. Reconhece, além disso, como requeria há dez anos o documento de políticas da UNESCO confirmado pela declaração da CMES de 1998, que a educação é um conjunto, que seus elementos não podem ser separados, que uma reforma da educação, para ser válida, deve atingir todos os seus níveis, que a educação superior, bem conduzida, reforçará a coesão social.

Mas, banco é banco, e mesmo estes funcionários tão dedicados e tão honestos na tentativa de se aproximar da realidade social não conseguem dar um salto maior. No final do percurso, "at the end of the day" como dizem os anglo-saxões, as soluções continuam as mesmas. A 
Dez anos de antagonismo nas políticas sobre ensino superior...

diversificação institucional com prioridade à privatização, o compartir de custos, sinônimo de estabelecimento de cobrança da educação, é sempre enfatizado; as medidas propostas não serão capazes de evitar o elitismo nem de estabelecer sistemas de cooperação que sejam realmente solidários.

Não há dúvidas de que é um documento progressista caso se compare com seu similar de 1994. Mas é um documento que não pode satisfazer a quem considere a educação superior um bem público. Nele, seus autores lançam a idéia bastante ambígua de que educação superior é um bem público global. Como bem assinalaram participantes latinoamericanos na Conferência Paris + 5, a qual, em junho de 2003, revisou e confirmou as opções feitas pela Conferência Mundial de 1998, bem público é uma coisa, bem público global pode significar outra coisa completamente diferente. Aquele pode representar a cooptação de um movimento amplo, com raízes sociais profundas, que requer autonomia e independência, quando o "bem público global", em tempos de OMC, pode muito bem significar uma volta a um período de uniformidade cultural.

Não há que se esquecer de que tal definição foi feita no momento mais intensivo dos debates sobre as propostas levantadas na Organização Mundial do Comércio, as quais podem, segundo muitos, transformar a educação em simples mercadoria. Bem público global, no momento em que um pequeno grupo de instituições dominadas justamente por países industrializados e apoiado por departamentos do atual governo norte-americano e por instituições como a OCDE e o Banco Mundial, os quais tentam definir o que é qualidade com base na experiência de alguns poucos Estados-membros da OCDE, não é expressão de natureza a assegurar aos que pensam que educação é um direito que eles terão ganho de causa com o novo conceito. Bem público global pode, sim, significar a adoção de medidas neocolonialistas, inaceitáveis em pleno século XXI.

Tal suposição é reforçada quando, ao se analisarem as propostas concretas formuladas pelo novo documento, justamente as que, por certo, receberão tratamento prioritário nos programas de financiamento do Banco, a primeira delas repete, em sua integralidade, o que já havia sido fixado no documento de 1994 , ou seja, o crescimento da diversificação institucional por meio da ampliação de instituições não-universitárias e de instituições privadas. 


\section{Evolução no que se refere à UNESCO}

Do lado da UNESCO, depois de 1994-1995, os esforços concentraram-se na preparação e organização da Conferência Mundial sobre o Ensino Superior, por meio de um amplo processo participativo ao qual estiveram associados os governos dos Estados-membros da organização, entidades não-governamentais interessadas de alguma forma no ensino superior, representantes do mundo acadêmico, em particular de dirigentes universitários, professores e estudantes, representantes da sociedade civil em geral.

Muito já se falou sobre a CMES. Ela, em realidade, consolidou uma longa tradição de apoio, dentro do sistema das Naçōes Unidas, à concepção de educação, em particular à educação superior, como um direito humano atribuído a todos, sem discriminação de espécie alguma, seja de raça, gênero, idioma, religião ou qualquer rejeição fundamentada em consideraçôes econômicas, culturais, sociais ou em handicaps físicos.

A CMES definiu alguns princípios fundamentais além da não-discriminação. Pertinência e qualidade devem vir sempre juntas, o estudante deve estar no centro do processo, a função dos professores deve ser valorizada, a qualidade leva em conta situaçōes concretas no campo sociocultural, sendo rejeitada qualquer tentativa de imposição de modelos únicos, as novas tecnologias devem ser utilizadas para facilitar a democratização, a cooperação baseada na solidariedade é fundamental nos dias de hoje. A educação superior é vista como um bem público e a função do Estado para garantir este conceito é considerada indispensável. Nos debates que precederam a CMES, ficou muito claro que a educação superior, para ser pertinente, deve contribuir para a busca de solução dos problemas importantes da sociedade e é parte de um sistema mais amplo, o sistema educacional, tendo ela responsabilidades a exercer para o bom funcionamento desse sistema em sua integralidade.

Uma olhada no que se passou nestes últimos dez anos e no que ocorre hoje, em nível mundial, revela que é importante bem definir o conceito de bem público e de serviço público que lhe é correlato. Ao tempo em que se promovia todo este debate, no marco da OMC, desenvolveu-se todo um sistema que, se levado às últimas consequiências, transformará a educação superior em simples mercadoria (ver número especial da revista Educação \& Sociedade publicado em 2003, n. 84, v. 24). 
Dez anos de antagonismo nas políticas sobre ensino superior...

Recentemente, funcionários da UNESCO, com a colaboração de servidores da OCDE e de alguns especialistas internacionais conhecidos por suas posições aparentemente neutras, elaboraram um documento ainda não oficializado pelos órgãos diretores da organização, no qual se escamoteia o sentido de bem público, no qual se omitem referências a instrumentos das Nações Unidas e da própria UNESCO mais favoráveis à concepção que foi sempre defendida pelos Estados-membros da organização, no qual se trata do problema da diversificação de uma maneira parcial muito próxima da visão dos documentos da OCDE e do Banco Mundial.

A posição oficial da UNESCO encontra-se, segundo pronunciamentos recentes dos responsáveis pelas políticas no campo do ensino superior, na declaração da Conferência Mundial de Paris, realizada em 1998, ratificada em 2003. No entanto, estamos assistindo a um movimento mais para consolidar, no nível de todas as organizações, um pensamento único?

\section{Perspectivas e perplexidades}

Fazer futurismo nestas matérias não é tarefa fácil. Mas trata-se, sem dúvida, de mais uma missão a ser desenvolvida pela comunidade acadêmica e seus representantes, que devem esforçar-se para conhecer as tendências, analisar as manipulações e buscar orientações que assegurem ao ensino superior condiçōes para executar suas missões.

Deve-se observar também o que acontecerá com a idéia de elaboração de uma convenção, no marco da UNESCO, sobre a diversidade cultural. É evidente que uma das aplicaçôes concretas mais imediatas de uma convenção desta natureza será a necessidade de se respeitarem os aspectos culturais dos sistemas específicos de educação superior. Este princípio e esta defesa sempre tiveram guarida, dentro da UNESCO e agora no marco da OMC, entre um grupo de países, em particular os países em desenvolvimento membros, no passado, do Grupo dos Setenta e Sete.

Esta concepção parece ter sido também, sempre, a das delegaçôes de vários países desenvolvidos, entre eles o Japão, cujos delegados sempre tiveram especial atenção a medidas que pudessem prejudicar a especificidade de suas instituições de ensino superior, ao caráter único de sua cultura e à soberania do país. E, por certo, a visão de sistemas 
de educação superior pertinentes, compatíveis com as culturas de cada povo, sempre recebeu apoio entusiástico da comunidade acadêmica internacional.

Recebido e aprovado em setembro de 2004.

\section{Referências bibliográficas}

DIAS, M.A.R. Tendances et défis de l'enseignement supérieur : une vision globale. In: UNESCO. Le rôle de l' enseignement supérieur dans la société: qualité et pertinence. Paris, 1991.p.41-72. (Nouveaux cahiers sur l'enseignement superieur. Documentation des reunions 1).

EDUCAÇÃO: de direito de cidadania a mercadoria; novas leituras sobre o publico e o privado/mercantil. Educação \& Sociedade, Campinas, v. 24, n. 84, 2003. (numero especial)

FUNDACIÓN UNIVERSITARIA PARA LA COOPERACIÓN INTERNACIONAL (CRUE). Lecciones de la Conferencia Mundial sobre Educación Superior: perspectivas de la educación superior en el Siglo XXI. Madri: CRUE, 2002.

KENT, R. Dos posturas en el debate internacional sobre la educación superior: el Banco Mundial y la UnEsco. Universidad Futura, Mexico, v. 7, n. 19, p. 19-26, 1995.

OLSSON, B. The power of knowledge: a comparison of two international policy papers on higher education. In: BUCHERT, L.; KING, K. (Ed.). Learning from experience: policy and practice in aid to higher education. The Hague: Centre for the Study of Education in Developing Countries, 1995. p. 235-246. (CESO Paperback, n. 24).

SALMI, J. Reformas en educación superior: experiencias y lecciones internacionales. Lima: Pontificia Universidad Católica del Perú, 1994.

SOLER ROCA, M. Dos visiones antagónicas de la educación desde la atalaya internacional. Barcelona: Edición del autor, dic. 1997. (Publicado com autorizacão da revista Voces, Montevideo, v. 1, n. 2).

UNESCO. Division of Higher Education. Strategies for change and development in higher education: policy paper on higher education. 
Dez anos de antagonismo nas políticas sobre ensino superior...

In: UNESCO-NGO Collective Consultation on Higher Education, $3^{\text {rd }}, 9-11$ december 1992, Paris. Proceedings... Paris: unesCO, 1993. (New papers on higher education; meeting documents n.5).

UNESCO. Policy paper for change and development in higher education. Paris, 1995. Disponível em: <unesdoc.unesco.org/images/0009/ 000989/098992e.pdf> Acesso em: out. 2004. (editado também em francês, espanhol, russo, chinês, árabe, japonês e português.

UNESCO. L' enseignement supérieur au XXI Siècle: vision et actions. In: CONFERENCE MONDIALE SUR LENSEIGNEMENT SUPERIEUR, 1998, Paris. Rapport final. Disponível em: <www.unesco.org/ education/educprog/wche/principal/ag-21-f.html> Acesso em: out. 2004. (Texto também em inglês e espanhol).

UNESCO. Tendências da educação superior para o século XXI. In: CONFERENCIA MUNDIAL SOBRE O ENSINO SUPERIOR, 1998, Paris. Anais... 2 ed. Brasília, DF: UNESCO; CRUB, 2003.

WORLD BANK. Higher education: the lessons of experience. Washington, DC, 1994.

WORLD BANK. Prioridades y estrategias de educación: examen del Banco Mundial. Washington, DC, 1996.

WORLD BANK. Higher education in developing countries: peril and promise. Washington, DC: The Task Force on Higher Education and Society, 2000. Disponível em: <www.tfhe.net/index.htm> Acesso em: 2004.

WORLD BANK. Constructing knowledge societies: new challenges for tertiary education. Washington, DC, 2002. Disponível em: <www1.worldbank.org/ education/tertiary/documents/Constructing\%20Knowledge\%20Societies.pdfs Acesso em: 2004. 